Editorial

\title{
Cirujanos de Mano del siglo XXI
}

\section{Century Hand Surgeons}

\author{
Joaquim Casañas ${ }^{1}$ \\ ${ }^{1}$ Unidad de Traumatología y Cirugía Ortopédica, Centro Médico \\ Teknon, Barcelona, España
}

Rev Iberam Cir Mano 2018;46:85-86.

El devenir de los tiempos y este concepto llamado globalización ha hecho que en muy pocos años, nuestro entorno haya cambiado de forma muy considerable. Nuestra profesión, y así me gustaría llamarla siempre, se ha visto envuelta en una serie de cambios de parámetros en nuestro ambiente, que hace que nos encontremos con estándares de actuación realmente chocantes e inimaginables hace poco tiempo y sin ningún sentido común.

Los que llevamos unos cuantos años de ejercicio y que, por lo tanto, tenemos perspectiva de evolución y capacidad de análisis, no podemos dejar pasar la oportunidad de expresar y sembrar la semilla de la reflexión de "a dónde vamos". Toda esta evolución y cambios no es más que el giro y el devenir de una rueda en la que nos encontramos como sociedad, país y entorno. Pero, así como en ciertas ocupaciones y profesiones pueden ser dolorosos e incluso drásticos tanto en el ámbito laboral y económico, en nuestra profesión llega a alterar la relación de la esencia de nuestra actuación y hace difícil llegar a imaginar cuál será el techo y las circunstancias en el que se acabará desarrollando nuestra profesión.

Pongamos las bases de donde partimos. Nuestra profesión está basada en la relación médico-paciente, y esa es la esencia de todo. Esa relación permite establecer canales de confianza y de comunicación fluidos para solucionar las dolencias de nuestros pacientes en un ambiente tan próximo como sea posible. Esa relación se establece tanto en el ámbito de la sanidad pública, como en la sanidad privada. Por desgracia, en los dos entornos, se han dado fenómenos de gestión de la información y del control del gasto que han contribuido en gran manera a diluir nuestra presencia. La informatización y gestión de datos no tiene discusión en el beneficio que han aportado para la mejor praxis y seguridad de nuestra actuación, sin embargo, han estado en muchas ocasiones diseñados para control del gasto y de la productividad, especialmente en la sanidad pública. Ello ha hecho que muchas veces, la utilización de sistemas cuyo fin no ha sido el mejorar nuestro desarrollo profesional sino el

Address for correspondence Joaquim Casañas, MD, Unidad de Traumatología y Cirugía Ortopédica, Centro Médico

Teknon, Barcelona, España

(e-mail: dr.casanas@traumaunit.es). control de la actividad y la medida del ajuste al presupuesto sea visto con desgana por parte del médico e incluso haya sido perjudicial para el desarrollo de la profesión y las condiciones de trabajo.

En la mayoría de las ocasiones, esa implantación de sistemas se ha hecho de espaldas a cualquier asesoramiento médico. Dejar fuera al profesional es una oportunidad perdida, ya que esos sistemas de medida permitirían una adecuada ejecución de las prestaciones técnicas, que mejorarían nuestra actividad, la capacidad de seguimiento de los casos, la obtención de datos de resultados y consecuentemente, mejorarían la eficacia de las actuaciones médicas y directamente el gasto, la eficacia y la eficiencia.

Las relaciones laborales también han cambiado. En el ámbito público, la relación médico-organización, es una relación laboral con una asimetría descomunal entre el individuo como unidad y la organización como administración del estado. Ese fenómeno también está comenzando a ocurrir en la sanidad privada. Vamos a analizar ese fenómeno brevemente.

Desde los años 70 hasta hace poco, en España, la sanidad privada estaba acaparada por una mayoría de profesionales que complementaban su actividad pública con ansias de una mejora económica del sueldo laboral público y algunos pocos que rechazaban el entorno y el método de actuación de la sanidad pública, y desarrollaban toda su actividad en la sanidad privada donde encontraban, en lo bueno y por lo malo, libertad de actuación. Ese dibujo inicial ha ido cambiando con el paso del tiempo y se ha ido pasando de una especialización de ofrecimiento de servicios por parte de los profesionales con actividad compartida público-privada, a la unión de profesionales para compartir gastos, operativas y estructura y, por último, a la formación de grupos médicos organizados y robustos, con un portfolio completo de servicios y con estructuras societarias organizativas y fiscales en el entorno de un servicio médico o quirúrgico que nada tendría que envidiar a los servicios de los hospitales públicos. Es decir, una unión que daba una fuerza con poder de negociación frente

Copyright (C) 2018 Thieme Revinter Publicações Ltda, Rio de Janeiro, Brazil

License terms

OI https://doi.org ISSN 1698-8396. 
a aseguradoras y clínicas, no en el concepto del volumen sino en el concepto de servicio y calidad.

Pero ese modelo se empezó a fracturar recientemente, no hace más de 5 o 10 años que ese modelo tristemente se resintió en los dos ámbitos, tanto en el público como en el privado. El origen de esa inflexión vino de la mano de la crisis económica que afectó a nuestro país y a Europa. El flujo de capital se resintió de sus inversiones con retornos del 10\%$40 \%$ anuales en sectores como la energía, el inmobiliario y el financiero y empezó a buscar valores refugio con porcentajes de beneficio más bajos, pero más seguros. Por desgracia nuestra, la sanidad es uno de esos valores con márgenes de alrededor del $7 \%$ anuales. Los grandes grupos de capital de riesgo empezaron a buscar valores seguros tanto en el ámbito de las compañías aseguradoras como de los servicios de diagnóstico, transporte, y sobre todo de clínicas, siendo ese fenómeno totalmente global y afectando en diferentes momentos y velocidades, tanto a Europa como a Sudamérica.

En ese escenario, el médico es cada vez el elemento más débil del trípode proveedor de servicios grupos sanitario (público-privado) -proveedor financiero (administraciónaseguradoras) y así lo será si no reinventamos los parámetros de la profesión adaptándolos al escenario actual.

Por último, existe otro fenómeno que interactúa con esos hechos explicados anteriormente sobre el cambio en los sistemas de información y entrada de capital en nuestro entorno. Se trata de la digitalización, la comunicación mediática y su gestión. Estamos sometidos a un alud de información y de gestión de redes sociales. Además, la legislación vigente en cuanto al manejo de los datos es de muy difícil cumplimiento tanto en el ámbito público como en el privado, y genera sanciones económicas de valor muy importante.

Actualmente, estamos sometidos a una presión de distintos elementos que tienen mucha fuerza y que pueden alterar la relación médico-paciente y la satisfacción exclusiva de poder mejorar la vida de nuestros pacientes. Y por supuesto que también no debemos perder jamás la ética de ese principio.

¿Cómo debemos reaccionar, para colocarnos en la línea de actuación necesaria que se nos demanda, sino queremos ser totalmente anulados como individuos, colectivo y profesión? No existe una fórmula mágica para ello, ni cualquiera de las propuestas que se hagan son sinónimo de éxito. En cada entorno nacional y local será diferente, pero en esencia debemos adaptarnos a los nuevos estándares y reglas de juego. Es aquí donde como colectivo de sociedad médica y científica que es la SECMA, debemos impulsar la adaptación de los profesionales para orientarnos a esa realidad y para ser competitivos.
Nuestras herramientas de mejora pasan por la calidad, la competitividad, la unión y la comunicación, haciendo participes a la sociedad civil. Nuestro país, como muchos otros de la esfera latina, tiene vicios políticos que será muy difícil cambiar a corto plazo. Existen intereses incluso supranacionales que hacen que nuestro Estado y nuestros políticos sean insensibles a la relación médico paciente o dicho claramente, de servicio a la sociedad. Pero no por ello hemos de perder nuestro objetivo, nuestro fin es tan fuerte que será una realidad.

Necesitamos disponer de una comunicación fluida entre nosotros, para poder ser un grupo operativo de calidad y este término de grupo, lo debemos extender de manera plástica. Es más fácil movilizarnos por un objetivo definido que no por grandes ideas. Nuestro objetivo ha de ser convertirnos en un grupo de especialistas en técnicas y conocimientos médicos, y que sepamos controlar la información, porque somos partícipes de su gestión, y que tengamos conocimientos de gestión tanto en el entorno público, privado, de proveedores y de grupos sanitarios controlando el mundo de la comunicación digital y la imagen corporativa, haciendo participe a la sociedad civil, nuestro gran aliado que es quien se beneficia de la relación médico-paciente.

Como se lleve a término esa idea, variará en cada microambiente. Jamás podrá ser igual en grupos de hospitales públicos, de asistencia al mundo laboral o de hospitales privados y variará entre países y regiones, pero la idea general de la confluencia ha de prevalecer.

El entorno no lo pondrá fácil, como nada es fácil en la vida. Como digo muchas veces, lo fácil es visitar y operar, pero nos hemos de implicar en la gestión. Somos los mejores gestores de nuestra actividad y ellos lo saben y por eso recelan. Es una vergüenza que desde que terminé mis estudios de licenciatura en 1987, el programa de pregrado incluya tantas asignaturas de gestión de modelos sanitarios o económicos como cuando yo estudié, es decir ninguno. ¿Por qué?

Resistirse a la evolución, por poco que nos guste la dirección que toma, es absurdo. Hemos de buscar los rebufos de las olas para surfear en ellas y montarnos para encontrar nuestra ubicuidad en el momento actual, la unión por parámetros de calidad y especificidad con control de la información y conocimiento del entorno es nuestra gran oportunidad. Somos los mejores gestores de la sanidad, pero nos hemos de implicar y aprender a compartir asistencia, investigación, ciencia, comunicación, emprendimiento y gestión. Tenemos la gran ventaja desde SECMA de agrupar a unos pocos que solo ellos saben hacer bien lo que hacen y lo que haremos en los próximos años para que con las herramientas actuales nos conozcan. 